\title{
Antropólogos, missionários e imagens do continente africano: entrevista com Eric Morier-Genoud
}

\author{
ERIC MORIER-GENOUD \\ QUEEN'S UNIVERSITY BELFAST, BELFAST, REINO UNIDO \\ HTTPS://ORCID.ORG/0000-0002-9680-098X
}

VICTOR MIGUEL CASTILLO DE MACEDO

MUSEU NACIONAL/UNIVERSIDADE FEDERAL DO RIO DE JANEIRO (UFRJ), RIO DE JANEIRO/RJ, BRASIL

HTTPS://ORCID.ORG/OOooo-000I-6923-0734

\section{FRANCIELI LISBOA DE ALMEIDA}

INSTITUTO FEDERAL DO PARANÁ (IFPR), PARANAGUÁ/PR, BRASIL

HTTPS://ORCID.ORG/0000-0002-69I0-2676

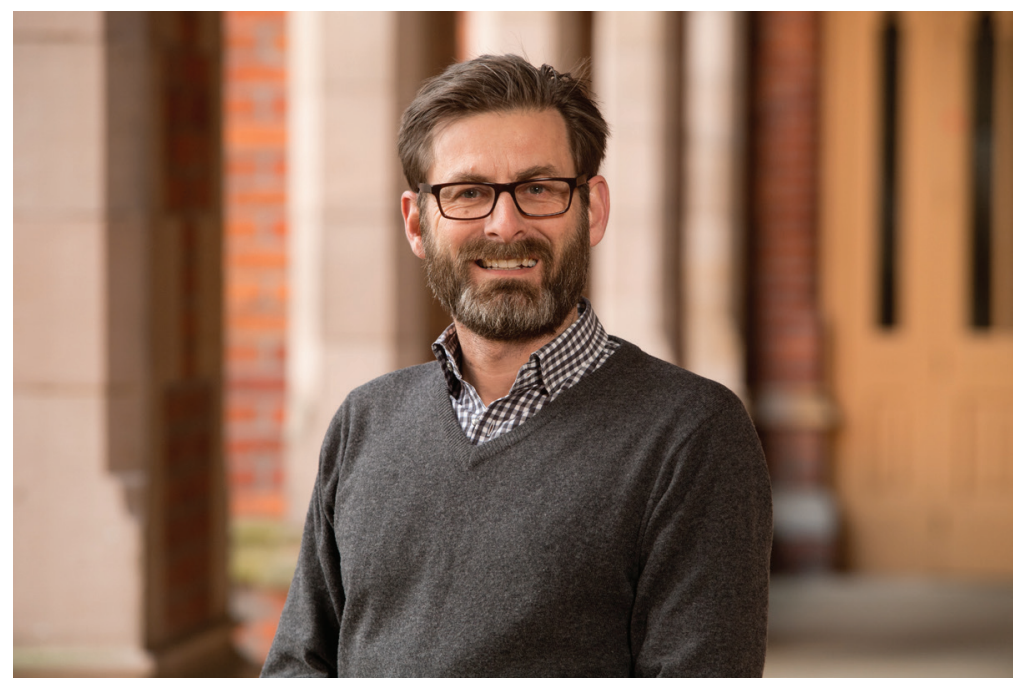

Eric Morier-Genoud. Queen's Belfast University - UK.

Créditos de imagem: Parkway Photography Ltd.

Eric Morier-Genoud é Senior Lecturer na Queen's Belfast University, Reino Unido, e esteve entre julho e agosto de 2018 como Professor Visitante do Departamento de Antropologia da UFPR. Com uma trajetória intelectual interdisciplinar, entre a Ciência Política, a Sociologia e a História, o profes- 
sor Morier-Genoud foi também fundador e editor-chefe da revista Social Sciences \& Missions (Leiden: Brill). Em sua formação teve contato com alguns dos principais pesquisadores e especialistas sobre o continente africano, entre eles: Patrick Harries, Jean François-Bayart e Georges Balandier. Publicou, em 2020, Convertir l'empereur? Journal du missionnaire et médecin George-Louis Liengme e, em 2019, a monografia Catholicism and the Making of Politics in Central Mozambique, 1940-1986. Antes editou Imperial Migrations: Colonial Communities and Diaspora in the Portuguese World (em 2012, em parceria com o historiador Michel Cahen) e Sure Road? Nationalisms in Angola, Guinea-Bissau and Mozambique, publicado no mesmo ano. Em 2011, em colaboração com Didier Péclard e Caroline Jannerat publicou a monografia Embroiled. Swiss Churches, Apartheid \& South Africa.

Com uma experiência já consolidada na pesquisa sobre África, o professor Morier-Genoud faz parte de uma geração de pesquisadores interessados em desenvolver perspectivas que compreendam a realidade africana de modo a não se fechar em campos disciplinares. Assim as formas pelas quais a religião interpela a política no contexto moçambicano, ou a circulação de visões de mundo, objetos e estratégias de vida, dentro do contexto missionário suíço do período colonial, são enquadramentos que o interessam, entre outros.

Em sua estada no Brasil, o professor ofereceu à comunidade da UFPR o mini-curso "Visualidades e violências na África: novas abordagens" que se dividiu entre os módulos "A Fotografia como fonte histórica e antropológica" e "Novas abordagens sobre a Guerra Civil em Moçambique”, que atraiu estudantes de outros departamentos, como os de História e Sociologia. Aproveitou também para lançar sua obra, organizada com Michel Cahen e Domingos Rosário, The War Within: New Perspectives on the Civil war in Mozambique 1976-1992. Seu próximo projeto é lançar uma edição crítica do diário do médico missionário suíço, George Liengme, que ficou três anos na corte do imperador Gungunhane antes da sua conquista pelos portugueses - no que hoje é o território moçambicano. Aproveitando sua presença em Curitiba, realizamos essa entrevista ${ }^{1}$ que percorre e abre caminhos possíveis para pesquisas antropológicas com documentos. É um encontro de diferentes lusofonias (o português africano e brasileiro) e certamente interessa a pesquisadores ou futuros interessados em investigar o continente africano.

\section{Trajetória}

Podemos perceber que os seus temas de pesquisa se concentram em grande medida em Africa, seja a questão da relação entre Antropologia e as missóes ou então a guerra civil em Moçambique. Em que momento da sua trajetória surgiu esse interesse pela Africa e mais particularmente por Moçambique?

1 Entrevista realizada em 13 de agosto de 2018 nas dependências do Departamento de Antropologia da Universidade Federal do Paraná, Curitiba. Agradecemos a prontidão com que o prof. Morier-Genoud aceitou o nosso convite para essa entrevista, realizada a poucas horas antes do seu embarque de retorno a Europa, bem como a paciência e generosidade nas sucessivas revisões que realizamos até concluirmos o material. Agradecemos também Gustavo Anderson e Flávia da Rosa Melo pelo excelente trabalho na transcrição dos áudios. 
EMG: Essa é uma história um pouco complicada, com muitas vias. Mas digamos assim: tive um interesse antigo, da juventude, pela África assim como pela América Latina. Hesitei muito entre os dois continentes. Antes de entrar na universidade, tirei um ano sabático para fazer o serviço militar, como todos tínhamos que fazer naquela altura na Suíça, e viajar um pouco. Fiz o serviço militar, trabalhei e decidi ir para a África. Viajei à África austral onde fiquei uns três meses, visitando o Zimbábue, a África do Sul, a Namíbia e Moçambique. Neste último país havia uma guerra, que parecia muito complicada, a qual a literatura parecia ter dificuldade em explicar, o que suscitou o meu interesse. Entrei na universidade de Lausanne, na Suíça, em 1989, e lá procurei fazer o máximo de aulas relacionadas à África. Tive a chance de ter vários professores trabalhando com o continente. Em Lausanne tive aulas com o grande antropólogo francês Georges Balandier, com o grande cientista político Jean-François Bayart e com o historiador sul-africano Patrick Harries. Tanto o Bayart quanto Patrick Harries viraram meus mentores nos anos seguintes. Assim consegui cedo me especializar sobre a África. É, portanto, sem grande surpresa que decidi, no fim dos meus estudos, ir fazer um mestrado na School of Oriental and African Studies em Londres. O mestrado não saiu exatamente como queria, daí decidi ir viver e trabalhar em Moçambique. Fiquei lá 3 anos até surgir uma oportunidade (em 1997) de ir fazer um doutoramento nos Estados Unidos.

Comecei a universidade em 1989, portanto, o meu desenvolvimento intelectual é dos anos 90. Gramsci estava muito na moda e o debate era sobre as questões de estruturas, de agência e de cultura. Entrei um pouco na sociologia neo-gramsciana, já que Gramsci era dos poucos marxistas que tinha consideração plena para a cultura e a religião. No Reino Unido apanhei o "cultural turn" que estava a correr, onde a obra de Edward Said foi central para consolidar de vez o meu interesse com os assuntos de cultura, identidade e religião. Há uns anos James Beckford me classificou como sendo promotor de uma perspectiva de "oportunity structure", ou seja, adepto de estudar a maneira como as pessoas agem dentro de estruturas ${ }^{2}$. Acho esta descrição correta, pois o que me interessa é estudar as escolhas que as pessoas fazem dentro de constrangimentos existentes. Portanto, não é nenhum individualismo metodológico onde as pessoas escolhem supostamente de maneira livre o que querem fazer, nem é um estruturalismo que determina tudo e não deixa espaço a escolhas individuais. Mais, eu creio que as pessoas não só agem dentro de estruturas, mas que elas produzem estruturas pelas suas ações. Indivíduos são, ao mesmo tempo afetados e limitados pelas estruturas, e afetam e alteram pelas suas ações estas mesmas estruturas que são, de fato, dinâmicas.

Para o meu doutoramento, fui aos Estados Unidos no Departamento de Sociologia da State University of New York at Binghamton. Ofereceram-me oportunidade e um financiamento. Binghamton tinha um Departamento de Sociologia famoso com Immanuel Wallerstein e toda uma equipe a trabalhar na linha da Teoria do Sistema-Mundo, que é um tipo de mega ou meta-estruturalismo, o que não encaixa muito bem com a minha perspectiva. Mas eu fui lá para trabalhar como um professor em particular, o Martin J. Murray, que fazia (e ainda faz) pesquisa sobre a África do Sul, sobre memória e urbanismo. Ele, assim como uns outros tantos professores naquele departamento, como o James Petras, eram adeptos de um outro tipo de marxismo ou de pós-marxismo, no qual me encaixei bem.

2 Sobre esse tema ver James A. Beckford (2003:95-96). 
Sobre a África, vale a pena referir também que não só fui lá em 1989 e entre 1995 e 1997, mas também que tive a oportunidade de trabalhar em arquivos missionários, o que me facilitou o trabalho de pesquisa. Durante meu mestrado, não tinha assim muita vontade de estudar a religião - tinha interesse em estudar a guerra em Moçambique. Mas fui nos arquivos e usei o material à contra corrente (against the grain) para pesquisar o que me interessava. Para o meu mestrado, estudei a relação do governo moçambicano com as igrejas cristãs. A experiência foi muito boa e o assunto me interessou muito. Isso me levou, com o tempo, a desenvolver pesquisa mais voltada a religião.

Em resumo, este foi o mundo intelectual no qual me formei, e que me levou a trabalhar com religião, identidade e cultura em África. Uma mistura de escolhas pessoais, oportunidades, influências intelectuais e de mentores. Sem esquecer o estímulo que este tipo de pesquisa me trouxe e que continua a me trazer ao tentar entender como pensar o Outro e outras sociedades, como pensar a si próprio e sua própria sociedade, e como pensar problemáticas humanas fundamentais tais como a violência, a fé e as práticas religiosas, e a política.

\section{Diante dessa experiência moçambicana nos anos de formação, de que forma a África do Sul, as biografias de Henri-Alexandre Junod e seu filho Henri-Philippe Junod passaram a compor seus interesses de pesquisa?}

EMG: Mais uma vez, é uma mistura de motivações pessoais, oportunidades e interesse intelectual. Havia em Lausanne, a cidade onde cresci e estudei, o arquivo da missão suíça que continha os documentos dos dois Junod: Henri-Alexandre, o pai, e Henri-Philippe, o filho. O arquivo estava aberto e muito acessível. Sob encorajamento do professor Patrick Harries, que lecionava História Sul-Africana na Universidade de Lausanne (na altura, escrevendo o seu livro sobre Henri-Alexandre Junod "Butterflies \& Barbarians" (Harries 2007)3), eu decidi ir trabalhar não só neste arquivo como também me aprofundar sobre o Henri-Philippe Junod. De fato, Harries estimulou uma nova geração de historiadores numa linha de história cultural e intelectual assim como transnacional. Em 2003 ele organizou uma conferência muito importante em Basileia, na Suíça, sobre a cultura imperial neste que era um país sem império (a Suíça) ${ }^{4}$. Era muito inovador e foi quando apresentei pela primeira vez o meu trabalho sobre a história de Junod filho, que virou um artigo mais tarde (Morier-Genoud 2011).

A trajetória de Henri-Philippe Junod é a de um sujeito cuja história merece ser conhecida com a formulação de uma biografia intelectual e transnacional. Nascido em Moçambique onde o pai era missionário, ele foi mandado cedo à Suíça para estudar. Adulto, decidiu seguir o caminho do pai e foi viver e trabalhar como missionário em Moçambique, onde fez vários estudos etnográficos. Por razões de saúde na família, ele acabou por ir viver na África do Sul onde continuou a publicar até a crise e separação entre a Antropologia e os missionários no fim dos anos 1920. Sentindo-se marginalizado, ele deixou a escrita e contribuiu para lançar a Liga Penal Sul-Africana cuja meta era combater a pena de morte. Pouco depois começou a trabalhar com a Cruz Vermelha Internacional (CVI), sediada na

3 Sobre Patrick Harries na Suíça, ver Morier-Genoud (2015:11-13).

4 Em 2003 Patrick Harries organizou na Universidade de Basileia uma conferência intitulada "Imperial Culture in Countries without Colonies: Africa and Switzerland." 
Suíça. Foi ativo durante a segunda guerra mundial e depois no Quênia durante a guerra de Mau Maus. Considerado na Suíça como um grande antropólogo e "conhecedor dos africanos", foi chamado a Genebra em 1960 para dirigir o novo Instituto de Estudos Africanos, sediado lá, cuja meta era formar diplomatas africanos. Esta experiência, como a do Quênia, não correu bem e não durou muito. Mas a trajetória de Junod ilustra perfeitamente a circulação de homens e ideias entre a África e a Europa no século 20.

Voltando à pergunta, eu tinha um interesse por arquivos e desenvolvi interesse por assuntos missionários. Patrick Harries me puxou a focar em Henri-Philipe Junod. Ele não só me encorajou, como me mostrou os caminhos para uma perspectiva que transformava um assunto aparentemente fora da moda (os missionários) num assunto fascinante e inovador (história transnacional e intelectual) que era, na altura, a fronteira ou a frente da inovação intelectual.

\section{História e Antropologia}

\section{Como o professor vê a relação entre Antropologia e História? E como essas duas disciplinas marcam suas investigaçôes?}

EMG: Há duas vertentes em questão. Primeiro, a História da Antropologia sobre a qual falei no meu curso na UFPR. Esse foi um dos grandes interesses que tive no meu estudo sobre Henri-Philippe Junod, pois ele esteve num dos grandes momentos de ruptura entre a Antropologia e os missionários, e ele foi um dos atores da separação destes dois mundos, aceitando-a e pedindo aos teólogos para não abandonar a Antropologia, portanto, para desenvolver uma Antropologia especificamente cristã. $\mathrm{O}$ ponto aqui não é só de fazer a história de uma disciplina (ou de outra), mas sim de estudar a história da emergência das disciplinas profissionais. Este é um fenômeno recente, de um século atrás, quando disciplinas acadêmicas constituíram-se e profissionalizaram-se. Pierre Bourdieu falaria da emergência de um "campo" disciplinar, portanto, de áreas autônomas com as regras delas, com lutas para estabelecer estas regras, os limites do campo, e as regras da legitimidade dentro do campo (ou subcampo) científico.

Este tipo de pesquisa sobre a história das disciplinas me parece extremamente interessante e útil, na medida que todas as ciências (ou campos científicos) têm tendência a naturalizar a sua origem e sua existência, e a esconder conflitos e origens menos expressivos. Os antepassados muitas vezes são inventados e míticos. Numa disciplina que conheço bem, a Sociologia da Religião, há autores que tentam buscar intelectuais do século 18 para dizer que faziam Sociologia e que são, portanto, precursores da disciplina. Os homens citados, no entanto, não se concebiam como sociólogos (nem como cientistas, se calhar) e a subdisciplina da Sociologia da Religião simplesmente não existia. A própria palavra So-

5 O movimento dos Mau-Mau foi um grupo surgido entre a etnia Kikuyu (apesar de ter membros Merus, Kambas e Embus) que desenvolveu uma oposição violenta aos desmandos do colonialismo britânico de povoamento no território que hoje conforma o Quênia. Pode-se dizer que eles foram fundamentais na luta anti-colonial, uma vez que consolidaram a expulsão dos colonos brancos de grande parte das áreas rurais do Quênia. Para mais detalhes ver: M'bokolo (2011). 
ciologia não existia! Portanto, é preciso um processo de desconstrução e de reconstrução crítica das genealogias das disciplinas. Desconstruir coisas vistas como "naturais", estudar os debates e as lutas e, por fim, reconstruir a trajetória e evolução das disciplinas. As lutas não são, e não precisam ser físicas; neste caso são geralmente simbólicas, o que não é menos complicado ou violento.

No caso da Antropologia, penso que a história da Antropologia Missionária é particularmente interessante pela colaboração e depois separação (nos anos 1930 - onde os dois Junod tiveram um papel importante) que ocorreu em ambos os lados, porque na separação destas duas disciplinas entra o assunto da relação entre a fé e a religião, e as relações entre os dois, o que constitui um assunto fundamental de debate sobre o que é, e o que pode ser a ciência. Como sabemos, este é um assunto que não foi fechado com a profissionalização da Antropologia. O debate continua hoje. Pode haver ciência religiosa? Podemos ou temos que separar ciência e fé? Um cientista pode ter fé assumida ou deve se distanciar quando faz trabalho científico?

Agora a outra vertente da relação entre História e Antropologia tem a ver com a interdisciplinaridade. Virou grande moda nos últimos 20 ou 30 anos. Eu próprio tenho uma trajetória bastante interdisciplinar e gosto desta perspectiva. Comecei em Ciência Política, depois fiz doutorado em Sociologia, e agora faz 12 anos que eu ensino e escrevo História. De maneira interessante, antes de conseguir o lugar que eu tenho agora num Departamento de História, muita gente pensava que eu era historiador porque fazia pesquisa sobre tempos passados e trabalhava em arquivos. Às vezes parece que quem trabalha em arquivo só pode ser um historiador! Mas, ao mesmo tempo, devo dizer que minha experiência também mostra que há a barreira disciplinar que é às vezes muito difícil superar. Não tanto intelectual, mas social e institucionalmente. Primeiro, pelo menos no mundo acadêmico anglófono, as instituições gostam da ideia da interdisciplinaridade, mas depois têm dificuldade em colocá-la em prática. Instituições acadêmicas e de financiamento podem, pois, querer que a gente faça interdisciplinaridade, mas muitas vezes as realidades institucionais não deixam. Colaborar com alguém de outro departamento cria complicações senão problemas administrativos. Quem vai receber os créditos do ensino entre os departamentos que colaboram e como vão partilhar os fundos, por exemplo? Estes são assuntos quentes e muitas vezes barreiras muito difíceis de superar, mesmo que a instituição queira em teoria que a gente colabore intelectualmente. Segundo, há tradições, perspectivas e práxis diferentes entre as disciplinas, algumas delas também difíceis de superar. Historiadores trabalham em arquivos e antropólogos fazem observação participante. É verdade que há cruzamento de métodos, mas só até certo ponto. Estes métodos são, pois, constitutivos da identidade das disciplinas. Historiadores gostam do papel mesmo que façam também história oral, e antropólogos podem ir em arquivos, mas a observação (participante) continua sendo o método privilegiado da disciplina. E às vezes estas diferenças geram tensões: alguns historiadores acham que a maneira que os antropólogos fazem pesquisa é menos séria do que a deles. Antropólogos observam algo umas semanas e já vão escrever, enquanto "nós" vamos em arquivos meses, em vários arquivos, e levamos anos até escrever. Verdade ou não, estas ideias sobre o que acham os métodos mais legítimos criam tensões e desacordos.

Depois há também ciclos históricos quando uma disciplina está mais na moda do que outra. A História teve momentos onde era muito vívida e legítima, com debates interessantes, pensemos, por 
exemplo, na escola dos Annales ou na História Social. A Antropologia teve uma crise de legitimidade nos anos 1960-70 com as acusações de colaboração com o colonialismo e com os militares americanos no Vietnã, mas hoje está de vento em popa. Hoje é uma das disciplinas mais dinâmicas e férteis teoricamente, com inovações e debates muito interessantes sobre emoções, sons, consumo, performance, entre outros. Estes ciclos podem criar tensões, mas também levam a colaborações. E ainda bem que seja o caso, pois temos que ter capacidade de ouvir, aprender e deixar-nos inspirar por outras disciplinas - o que os anglófonos chamam de cross-fertilization. Testemunhamos isso historicamente: nos anos 1960 a Escola dos Annales se inspirou muito na Antropologia; e nos anos 1980 a Antropologia se inspirou bastante na História, até fundar em 1984 a revista Historical Anthropology.

\section{Missionários \& ciência}

O senhor identifica dois momentos da relação entre os missionários e a ciência: um que vai até o fim do século 19 aproximadamente, quando haveria uma sobreposição de campos e um trabalho colaborativo e, um segundo momento, a partir das primeiras décadas do século 20 em que há a separação e um tensionamento desses campos. Qual seria o ponto de inflexão marcador dessa mudança? E quais seus efeitos para a Antropologia e para a Missiologia, na experiência anglófona?

EMG: No mundo anglófono é muito claro que houve uma viragem no início do século 20. Eu identifiquei os anos 1920 até 1934 como sendo os anos da viragem definitiva, seguindo Patrick Harries. Vemos pois, a emergência do campo antropológico com a profissionalização da disciplina. Criaram-se cadeiras de Antropologia e departamentos de Antropologia nas universidades do mundo. A primeira cadeira dessa disciplina no mundo imperial inglês foi a de Radcliffe-Brown em Cape Town, África do Sul, em 1921. A seguir foi a de Winifred Hoernle, nomeada em 1923 na Universidade de Witwatersrand e a de Werner Eiselen, nomeado em 1926 na Universidade de Stellenbosch, ambas também na África do Sul. Juntos trabalharam para promover a disciplina, ensinando e formando uma primeira geração de antropólogos sul-africanos, e criando uma revista chamada Bantu Studies.

Eles estabeleceram a disciplina da Antropologia na África do Sul, com ligações fortes com o Reino Unido, e fizeram tudo para profissionalizá-la. Isso passou pelo estabelecimento de regras e métodos, afirmando, por exemplo, que a Antropologia deve ter pretensões teóricas e não pode ser somente empírica. Tem que ter como meta compreender e não mudar as sociedades africanas - estávamos pois, no mundo colonial e imperial inglês. E para assentar estas distinções de meta e de métodos, os novos profissionais distinguiram-na dos métodos que seguiam os... missionários! Henri-Alexandre era o grande missionário-antropólogo na altura, reconhecido como tal, graças a sua obra The Life of a South African Tribe, publicada em 1912-13. Por isso Radcliffe-Brown veio a atacá-lo diretamente. Acusou os missionários de quererem mudar as sociedades (acabar com as “más” tradições, acabar com o 
alcoolismo, a poligamia, e, como diziam, as "compras de mulher" ou, seja, o lobolo ${ }^{6}$ ) quando deveriam, segundo ele, somente entender, explicar e desenvolver teorias.

A ruptura entre a Antropologia e os missionários se deu formalmente entre 1928 e 1934. Esta última data coincide com uma conferência em Johannesburgo na qual a "nata" da Antropologia nacional e internacional se reuniu, com a presença ativa de Bronislaw Malinowski, vindo de Londres para a ocasião. O filho de Henri-Alexandre participou da conferência, que ocorreu poucos meses depois da morte de seu pai. E nesta reunião ele entendeu que havia doravante uma separação profunda entre antropólogos e missionários. Embora não concordasse, ele aceitou esta separação forçada pelos profissionais da Antropologia. Decepcionado, ele escreveu no ano seguinte um artigo numa revista de Missiologia muito influente, a International Review of Missions, onde explicou a situação (e a conferência). Ele declarou no texto que aceitava a separação das esferas mesmo que achasse que era errado fazer ciência sem uma dimensão espiritual, e pediu aos missiologistas para não abandonar a Antropologia. Militou, portanto, para o desenvolvimento de uma Antropologia Cristã - separada da Antropologia acadêmica e secular.

Um tema que chamou muito a atenção em sua comunicação foi a intensa movimentação de objetos entre colônia e metrópole, orquestrada e praticada pelos missionários. Conforme demonstrado, os objetos de origem africana não serviam somente para as coleções de História Natural de museus do Estado, como também para museus missionários. Tendo esse contexto em vista, de que modo tais objetos eram adquiridos? Existem registros dessas transações?

EMG: Não é um assunto que pesquisei intensamente e sobre o qual publiquei. Tenho interesse, li sobre isso, visito museus com esse olhar e tento estimular estudantes a investigar o museu que está ao lado da nossa universidade (o Museu de História Natural de Belfast). Pois comerciantes e missionários foram grandes "contribuintes" de artefatos dos museus. Os administradores dos museus pediam a essas pessoas para trazer objetos para guarnecer os museus e suas exposições. Existem até hoje artefatos, e também registros, correspondências e documentos de pagamentos - com variação dependendo do museu. É um assunto importante e muito interessante porque até hoje estes objetos recolhidos existem e são expostos nos museus, muitas vezes sem desconstrução da história e das dinâmicas atrás deles, sejam elas as dinâmicas imperiais, coloniais, missionárias ou racistas. Portanto, é necessário conhecer esta história e integrar isto no museu de hoje para os visitantes poderem ter uma visão crítica destes objetos que são ainda muitas vezes apresentados como "neutros".

Agora no caso dos museus missionários, as coisas são um pouco diferentes, porque os missionários montaram os seus museus, com uma meta específica que é promover as missões, ilustrar um discurso sobre o cristianismo, e demonstrar a necessidade de cristianização do mundo. Portanto, escolhiam objetos específicos, muitos deles sobre adivinhação, para ilustrar um discurso sobre o "mal" da divinação, do "paganismo", e dos espíritos, um mundo que eles descreviam como sendo o da "escuridão", do "diabo", e que contrastam com o mundo "luminoso" do cristianismo e do Deus deles. Portanto, aí há

6 Lobolo é uma forma de casamento tradicional na região da África Austral - sobretudo entre Moçambique e África do Sul - que foi estudada, entre outros, por Radcliffe-Brown. Para uma discussão contemporânea à respeito do Lobolo em Moçambique, ver o trabalho de Paulo Granjo (2005) e Taibo (2012). 
uma escolha de objetos diferentes, há uma exposição e disposição de objetos diferente, e no final um museu diferente. Quem trouxe os objetos, neste caso, foram os próprios missionários e eles fizeram uma seleção na origem. Às vezes, no entanto, era o próprio museu missionário a pedir aos missionários para mandar ou trazer objetos específicos. Isto é também diferente dos museus seculares que compravam e expunham um material mais diverso e o faziam dentro de um discurso, explícito ou implícito, de uma "nação" que se situava num mundo físico, geográfico e humano global (colonial e imperial).

No Museu da Missão Suíça, em Lausanne, a coleção que podemos chamar hoje de "etnográfica" (e que foi recentemente entregue ao museu de História Natural da cidade onde estava a sede da missão), é constituída por muitos objetos do dia a dia de Moçambique e da África do Sul. Há certos objetos repetidos cinquenta vezes, enquanto outros objetos existem num único exemplar, seja por causa da dimensão do objeto ou porque eram considerados importantes (ou não) dentro do pensamento missionário da época. Há, portanto, aí uma história interessante dos objetos que foram trazidos, uma história da circulação dos objetos, que ilustra um pensamento sobre o mundo. Se os museus de história natural têm como meta expor uma visão social e política do mundo, os museus missionários tinham como meta uma visão religiosa do mundo, como é e como devia ser. Portanto, construíram-se representações do mundo que muitas vezes não foram desconstruídas completamente, que ainda subsistem em partes ou no total nas coleções do arquivo e às vezes mesmo nas exposições permanentes. Precisamos desconstruir esses discursos, materializados em coleções e exposições, em termos de religião, raça, classe, gênero, etc, e talvez repensar mais criticamente as coleções e as exposições.

Vale a pena notar que os missionários também faziam exposições e, ainda mais, exposições itinerantes. O museu é fixo, portanto, a gente tem que ir até o museu, o que limita a sua audiência. Por isso os missionários fizeram muito, no fim do século 19 e início do século 20, na Suíça, no Reino Unido e em Portugal (muito provavelmente no Brasil também) exposições que circulavam em todo o país. Algumas exposições reproduziam uma rua chinesa ou uma aldeia de palhotas africanas - existem ainda hoje algumas fotos destes eventos. Estamos perto aí dos "museus humanos" que existiram neste período também. Existem bastantes trabalhos acadêmicos sobre as exposições humanas ou "zoo humanos", e sobre museus seculares, mas muito pouco sobre os museus e as exposições missionários, que atingiam talvez mais gente e, como disse, tinham especificidades fortes. Seria bom haver mais pesquisa sobre eles.

\section{E as exposiçôes coloniais...?}

EMG: Houve também exposições coloniais e depois exposições nacionais. As exposições coloniais começaram em 1879 e houve nada menos de três exposições coloniais ou imperiais só em Portugal. Exibiam-se objetos e pessoas, numa dinâmica igual à que descrevi. Existem muitos trabalhos acadêmicos sobre estas exposições. O que pouco foi estudado ainda, sobre estas e outras exposições, é como os objetos e sujeitos destas encenações atuavam - pois não eram somente passivos. Há um livro muito interessante do Andrew Zimmerman que mostra que nos zoo humanos na Alemanha, os sujeitos africanos "expostos" entendiam isto com bastante distância crítica, como sendo um tra- 
balho, e uma oportunidade de viajar. Para a exposição, tiravam a roupa para corresponder à ideia do "primitivo", faziam o "show", e depois voltavam a meter a roupa e iam aos cafés ou bares onde conversavam normalmente entre eles e com alemães (Zimmerman 2001). Muita gente tem uma ideia um pouco miserabilista dos africanos, da gente da Oceânia ou da Ásia, ao serem trazidos para Europa, explorados e maltratados e acabou. Não há dúvida que houve exploração, mas Zimmerman mostra também um outro lado...

\section{Tinha um revés...}

EMG: Exatamente. Eles tinham consciência que iam fazer um "show" e, mesmo que explorados, eles aproveitaram para ganhar conhecimentos sobre o mundo. Desenvolveram novos conhecimentos das sociedades, e sobre as sociedades, onde foram trazidos e regressaram para terra natal deles com uma nova consciência e com novas ideias que lá partilharam. É fascinante. No fundo é parte da globalização, de uma fase da globalização dos séculos 19 e 20, onde nem toda gente podia viajar, pois o turismo de massa ainda não existia, mas onde se promovia uma consciência do mundo através de museus e de exposições tanto seculares como missionários. Uma criança ou um indivíduo que não tinha capacidade de viajar no mundo podia assim facilmente desenvolver uma ideia do mundo através de objetos, de imagens e de textos.

Ora mais uma vez, os missionários foram cruciais neste desenvolvimento. Há estudos que mostram que quase toda a população da Escócia, por exemplo, lia jornais de missionários, que tinham uma circulação extremamente alta. Era uma altura na Europa e nos Estados Unidos onde quase a maioria da gente ia à igreja no domingo, e quase todo domingo se falava de missões, se falava do mundo, se falava dos africanos, dos indianos, dos chineses, etc. A imagem que as igrejas construíram da África era negativa, mas também positiva. É um pacote complicado, que temos que desconstruir. O Patrick Harries mostrou no caso da Suíça como se formaram certas imagens, certos contrastes, alguns dos quais nós ainda carregamos - visão racial, nacional, de gênero, etc.

Portanto, para voltar à pergunta inicial, sobre os objetos dos museus, penso que eles seriam o ponto de partida da pesquisa. Tem que estudar a origem dos objetos, porque foram escolhidos, quais valores carregavam ou foram dados, para que visão do mundo? Desconstruir e entender porque um objeto está ali, entender a que concepção do mundo contribui, isto é, qual era o papel dele numa coleção e em um museu. Os objetos divinatórios, por exemplo, eram trazidos pelos missionários para fazer um contraste entre o "cristianismo luminoso" e a "divinação da escuridão". Era esse o contraste, para promover uma visão de um mundo a favor da evangelização cristã. O objeto só está lá para isso, imbuído desse valor. Não é um objeto etnográfico que reflete os valores dados pelos usuários originais, pelo contrário. Temos que desconstruir para melhor reconstruir o entendimento destes objetos. Em Belfast o museu de História Natural tem objetos missionários que são mostrados, ainda hoje, como se tivessem um valor neutro, sem passado, sem uma história. A legenda na exposição só diz que o objeto foi oferecido por um missionário, sem mais. Talvez temos que rever as legendas dos objetos para reconstruir esse sentido histórico e explicar esses valores que foram imbuídos dentro dos objetos. 


\section{Missionários \& fotografia}

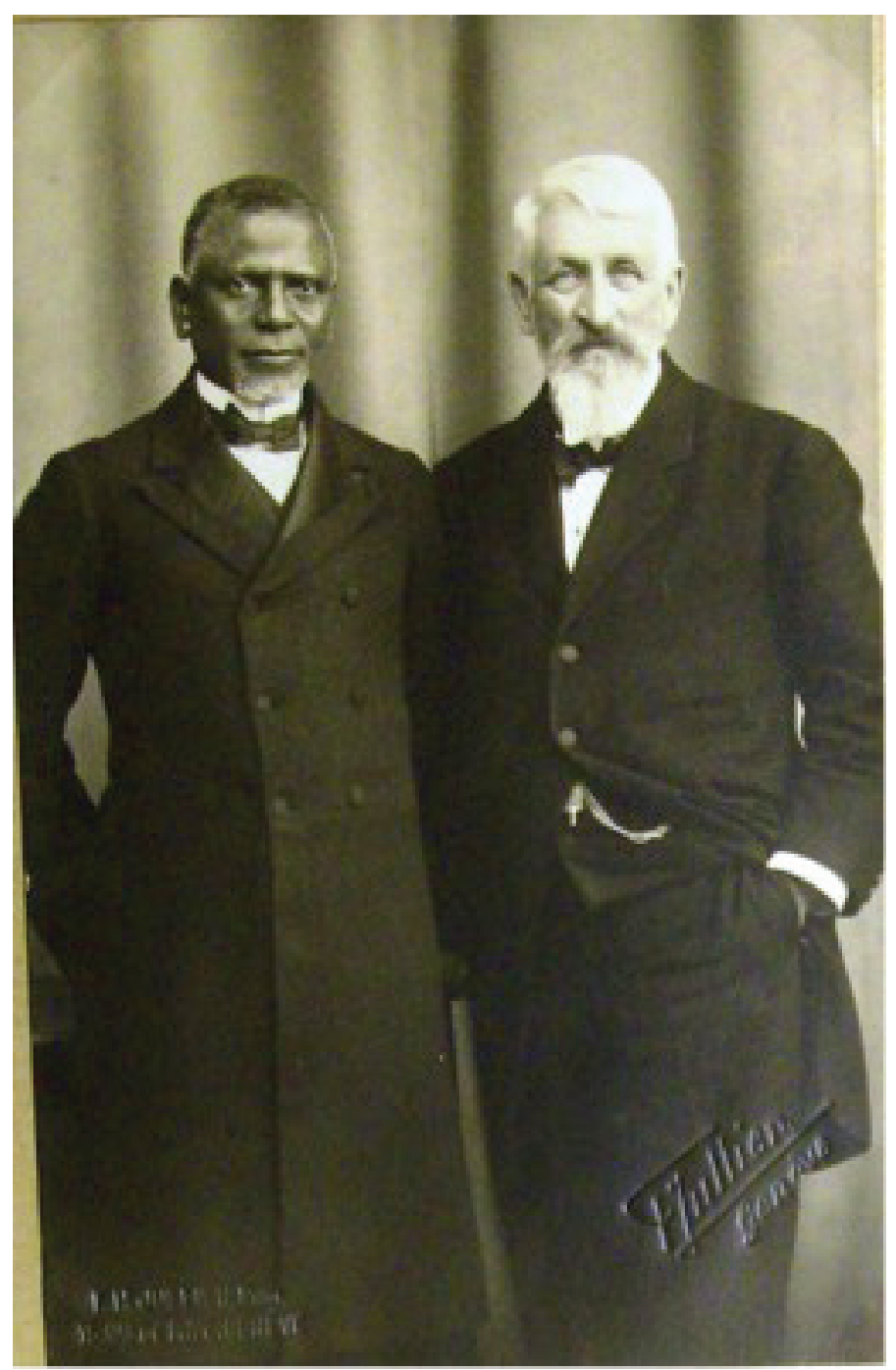

Figura 1. Calvin Mapopé e Henri-Alexandre Junod (Suíça; 1923). Fonte: Copyright DM-échange et mission (Suíça).

Professor, a fotografia de Calvin Mapopé condensa de certa forma a relação de diversos líderes africanos com os missionários cristãos no continente. No caso moçambicano existem alguns exemplos de personalidades e intelectuais que se beneficiaram da relação com as missöes, como o próprio Eduardo Mondlane. Quais elementos em comum podemos retirar dessas experiências entre africanos e missionários, que de certa forma se veem implicitos e explícitos, na imagem do pastor moçambicano com Henri-Alexandre Junod?

EMG: Há vários africanos importantes e influentes em Moçambique que se formaram nas missões cristãs. Entre os protestantes, temos Calvin Mapopé no início do século 20 e Eduardo Mondlane na metade do século. Outro grande intelectual foi Kamba Simango (que o professor Lorenzo Macagno e eu estamos a pesquisar) que se formou no início do século vinte nos Estados Unidos, em Hampton e depois na Columbia University. 
A fotografia do Mapopé com o missionário Junod é muito específica de um período. Existem fotografias iguais para Mondlane e para Kamba, fotos que são similares e ao mesmo tempo ligeiramente diferentes, dependendo do contexto, do período e da intenção do fotógrafo. Em geral existem em todas estas fotos uma hierarquia entre o missionário e o pastor uma vez que estávamos num período colonial - a maioria dos missionários não contestaram o colonialismo até muito tarde. No caso da foto do Mapopé e Junod, vê-se no entanto uma igualdade entre o missionário e o pastor africano. Uma igualdade simétrica - são vestidos da mesma maneira, pode-se dobrar a foto ao meio e os dois homens superpõem-se perfeitamente. Mas é uma igualdade exemplar, que representa um ideal. O ideal do cristianismo e o ideal da civilização. É o ideal da missão Suíça, uma missão adepta do cristianismo social, que acreditava que os africanos podiam ser educados e levados ao nível dos europeus com tempo e paciência. E um ideal racista, mas específico e menos "negativo" que os segregacionistas, por exemplo. Ora, esta foto do Mapopé teve muito sucesso na Suíça e foi reimpressa como postal durante décadas. É uma fotografia milimetricamente organizada, usando o Mapopé para mostrar o que a missão conseguiu fazer e, portanto, o que poderia fazer mais com outros africanos se a missão recebesse apoio e finanças para este trabalho.

Outra vertente interessante da fotografia é que Calvin Mapopé sabia o que fazia, tanto como Eduardo Mondlane e Kamba Simango, quando aceitou tirar esta fotografia assim como outras imagens. Mapopé não foi se meter com os missionários para ser humilhado. Ele tinha um interesse na foto e interesse nos missionários que lhe abriam novos mundos. Recebeu educação missionária, obteve um trabalho como evangelista, e viajou da região do sul da África até a Suíça. Portanto, a sua conversão abriu-lhe um "novo mundo" de oportunidades, não somente cristãs ou meramente religiosas, mas também sociais e políticas. O mundo cristão e missionário ao qual Mapopé, Kamba e Mondlane aderiram era um mundo de oportunidades sociais, religiosas, econômicas e políticas. Estes três homens expandiram os mundos deles ao entrar no mundo dos missionários. Kamba foi viver e estudar nos Estados Unidos em 1914, Mapopé foi à Suíça em 1923 e Mondlane foi estudar na África do Sul, em Portugal e nos Estados Unidos nos anos 1940 e 1950.

O caso de Kamba Simango é muito interessante. Eduardo Mondlane tem uma trajetória similar embora mais tardia. Os dois foram aos Estados Unidos através de redes missionárias, para uma educação em universidades americanas. Daí os dois desenvolveram, além do saber "tradicional" deles, novos conhecimentos e novas correntes tais como o ecumenismo, o nacionalismo, o pan-africanismo, etc. que os transformou em "cidadãos globais", como diríamos hoje. Eles não se converteram somente ao cristianismo e abandonaram o mundo do "paganismo"; eles entraram num novo mundo e entraram em redes internacionais, tanto geográfica, social quanto intelectualmente. Através do casamento dele nos Estados Unidos com uma mulher da elite ganense, Kamba foi introduzido no mundo da África Ocidental, do teatro, da música e dos filmes afro-americanos, do Harlem Renaissance e do pan-africanismo. Portanto, Kamba entrou num mundo global e bastante sofisticado. Calvin Mapopé não estudou na universidade nos Estados Unidos, mas frequentou um dos maiores seminários religiosos da África Austral, no Lesoto, e expandiu o seu mundo a nível regional, com uma consciência da região austral da África. E em 1923 viajou à Suíça por várias semanas, para celebrar o aniversário da Missão Suíça, 
mas também conhecer outras terras e outras culturas. Esta fotografia do Mapopé e do Junod foi tirada na Suíça em 1923, precisamente para celebrar o sucesso da missão, do seu pastor Calvin Mapopé, e a esperança de um mundo melhor graças ao cristianismo.

Há muitos africanos que viajaram pelo mundo antes destes três homens. Há histórias de africanos em todo mundo desde... sempre! Na Europa, na Índia, até no Japão. Há uma história fascinante de um moçambicano chamado Yasuke que chegou ao Japão em 1579 e que veio a ser o primeiro samurai negro da história. Na verdade a região que viria a ser Moçambique no século 19 lidava sobretudo com o Oceano Índico, e através dele com o mundo árabe e asiático. Foi o colonialismo português que reorientou parte da dinâmica e das redes deste território para Europa. Aliás, a colonização é isso mesmo: redirecionar as dinâmicas econômicas, sociais e culturais para as metrópoles - neste caso Lisboa. Mas a história nunca é linear, portanto, mesmo que o colonialismo português quisesse que tudo fosse ligado somente a Portugal, outros atores envolveram-se e atores africanos aproveitaram todas oportunidades, resultando que enquanto alguns foram para Portugal, outros foram para a Índia, para os Estados Unidos e para a Suíça. O mundo das redes existentes nunca foi completamente controlado por Portugal.

Um historiador americano que trabalha com religião, Derek R. Peterson, fez um trabalho inovador sobre os cristãos convertidos no African revival da África Central (Quênia, Ruanda, Uganda) (Peterson 2012). Ele mostra como os novos cristãos entraram numa rede mundial de comunicação através das igrejas, de cartas que escreviam a outros cristãos em todo mundo, e os debates que tinham nos jornais das igrejas. Estas comunicações expandiram o mundo destes cristãos e operaram muitas vezes fora, senão ao contrário, das redes coloniais. E, portanto, a mesma dinâmica, sem as viagens e os estudos fora do território. Muitos cristãos se converteram e expandiram o mundo deles através desta conversão (que não se resume a deixar uma fé para aderir a outra). É também transformação e expansão intelectual, social, econômica, e política. Esta perspectiva não tenta apagar, ou mesmo minimizar, a questão do colonialismo, da desigualdade ou da exploração. A questão é entender porque pessoas se converteram, com que efeito, e como as pessoas aguentaram em condições de colonialismo. $\mathrm{O}$ mundo é complexo, e o colonialismo foi altamente complexo.

Voltando ao Calvin Mapopé, Eduardo Mondlane e Kamba Simango, eles (como muitos outros) foram pessoas que conseguiram aproveitar o sistema colonial. $\mathrm{O}$ que não significa que aceitaram o sistema colonial. Aliás, sabemos que dois deles, Kamba Simango e Eduardo Mondlane, envolveram-se na luta anticolonial nos anos 1950 e 1960. Estes indivíduos são fascinantes porque tiveram um pé em vários meios, circularam no mundo, e contribuíram de maneira importante para a emergência do que podemos talvez ainda chamar de "modernidade" tanto ocidental como africana. Em termos acadêmicos, Kamba Simango ajudou muito os antropólogos europeus e americanos a escreverem sobre o sudeste africano. Ele trabalhou com Franz Boas, Natalie Curtis, Henri-Philippe Junod e Melville Herskovits para sua tese de doutoramento, entre outros. Eduardo Mondlane veio a estudar décadas depois com Herskovits nos Estados Unidos. O Calvin Mapopé ajudou muito Henri-Alexandre Junod (o pai) nas pesquisas dele. Portanto, estes africanos foram contatos, informantes e formadores de homens chaves do pensamento europeu sobre a África e pessoas chaves na emergência da antropologia profissional, como já discutimos. 
Estes africanos não só formaram estes intelectuais europeus e americanos. Eles influenciaram as ideias e as teorias destes intelectuais que mudaram com o tempo, sob influência destes africanos. $\mathrm{O}$ Henri-Alexandre Junod, por exemplo, era no início um grande evolucionista e difusionista, que achava que a África era o berço da humanidade ao mesmo tempo que estava num estágio muito atrasado da evolução. Com os anos, no entanto, ele aprendeu a apreciar as culturas e as histórias dos povos onde vivia, os lugares onde trabalhavam, e acabou revendo não só a sua apreciação destas sociedades e das culturas, mas também mudou as suas ideias evolucionistas. Vale a pena ler o livro do Patrick Harries sobre isso!

\section{Moçambique}

Passando ao bloco final de perguntas, recentemente o senhor publicou um livro com Domingos do Rosário e Michel Caben (2018) a respeito do que ficou conbecido como guerra civil em Moçambique. Na sua opinião, qual é a maior contribuição deste trabalho coletivo para estudo desse periodo em Moçambique?

EMG: A nossa meta com o livro tinha três vertentes. Primeiro, revisitar um tema que quase deixou de ser analisado na historiografia. Há pouquíssimos estudos sobre a guerra civil em Moçambique publicados hoje. Houve muitos estudos, artigos e livros durante o próprio conflito, mas o número diminuiu substancialmente após o acordo de paz de 1992. Houve perda de interesse por alguns, mas a maioria abriu-se para novos temas e problemáticas, tal como a desmobilização e reintegração dos soldados, a reconciliação da nação, a transição política, as eleições, a sociedade pós-guerra. Vinte anos depois achamos que era necessário revisitar o tema.

A segunda vertente relaciona-se com nosso desejo de complexificar o entendimento desta guerra, cuja narrativa popular virou bastante simplista. Teria havido uma única guerra, com "bons" e "maus", fatores internos e fatores externos, enfim... nada muito profundo e alinhado com os últimos desenvolvimentos na historiografia mundial sobre conflitos armados. Há, pois, toda uma nova literatura sobre as guerras mundiais e outros conflitos que desenvolveram novas perguntas e novas perspectivas, sobre cultura material, ecologia, combatentes, gênero, memória, entre outros, que precisam ser exploradas em relação a guerra civil em Moçambique. Achamos, portanto, que valia a pena revisitar este caso, para complexificar e abrir novas janelas sobre o tema. E o livro de fato conseguiu isto em parte, olhando para milícias populares, milícias privadas, gênero e as igrejas. Creio que restauramos alguma complexidade, diversidade e algum sentido de mudança e periodização da guerra civil em Moçambique.

A terceira vertente tinha a ver com novas fontes primárias. Vários autores da coletânea conseguiram encontrar novos arquivos que foram abertos recentemente. Arquivos de uma administração provincial ou distrital, arquivos de igreja, etc. Outros autores fizeram um trabalho sistemático e extensivo de entrevistas, facilitado pelo tempo que esgotou e tirou alguma tensão em torno do assunto. Vale a pena mencionar também que há várias memórias que foram publicadas que abordam a guerra e que nos pusemos a usar. Talvez o melhor exemplo, neste respeito, é o livro de memória de uma vítima do 
massacre de Homoíne, que conta a sua experiência, como sobrevivente, dia a dia, durante o massacre, e o período a seguir após ter sido raptado pelos guerrilheiros da Renamo (Armando 2018) ${ }^{7}$.

Portanto, novas perspectivas, novas fontes, com nova distância em relação ao período, achamos que valia a pena revisitar o assunto. Agora o livro não é resultado de um projeto de pesquisa, onde cada um teria tido fundos e tempo para uma pesquisa nova, conjunta e coordenada. O livro é fruto do encontro de várias pessoas com a mesma ideia, com trabalho específico de cada um. Significa que este não é um livro completo e definitivo revisitando a guerra de maneira extensiva, mas sim uma tentativa sistemática de relançar o tema à pesquisa com alguns frutos que esperamos abram janelas, mostrem resultados inovadores, e guiem caminhos para o futuro.

\section{No capitulo que o senhor escreveu fica evidente que a Igreja Católica participou não somente} das negociaçôes de paz na guerra civil, mas também participou ativamente dos seus dramas microssociais locais. Muito se falou das diferentes experiências que as regiöes de Moçambique tiveram com o advento da guerra. O senhor poderia comentar ou diferenciar o papel de protestantes e católicos nesse periodo?

EMG: A Igreja teve um papel tanto de vítima como de ator nesta guerra. A Igreja Católica é a maior instituição cristã de Moçambique, presente com paróquias e missões em todo país, portanto, não teve a escolha de se envolver ou não: ela foi envolvida. No caso de Inhambane, a guerra chega em 1982 e logo neste ano oito missionários foram raptados. Não por acaso: a guerrilha quis raptar missionários para uma operação de comunicação política nacional e internacional. Ora, isto logo criou um dilema ao bispo e ele decidiu fechar a metade das missões em sua diocese - as missões mais no interior. Portanto, logo no início, a guerra afetou a igreja e esta teve que se adaptar. Como eu mostro no capítulo, a Igreja Católica reagiu fechando algumas missões e reforçando as comunidades de base para cuidar dos crentes. Um novo sistema emergiu onde um padre ia uma vez por mês nas comunidades, ou as comunidades vinham à paróquia ou missão, para assim assegurar os serviços religiosos mínimos. Viajar às comunidades ou para missão era perigoso. Às vezes os padres assumiam riscos, às vezes eram os cristãos, sendo que estes foram menos mortos que aqueles.

A dinâmica das Igrejas Protestantes não foi muito diferente. Não houve tratamento diferente por parte da guerrilha ou do Estado. Houveram raptos e assassinatos tanto de padres quanto de pastores. Em ambos casos, houve também desenvolvimento da ajuda humanitária, particularmente a partir de 1984, após uma grande e mortífera seca no sul de Moçambique em 1982-83. A seguir a um pedido do Estado, começaram a vir ONGs religiosas de fora e desenvolveram-se braços humanitários tanto da Igreja Católica como do Conselho Cristão de Moçambique. O que foi diferente entre as instituições católicas e protestantes foi o posicionamento político público delas. Tinha muito a ver com a história

\footnotetext{
7 Renamo - Resistência Nacional Moçambicana (1975), também conhecida como a principal força política de oposição à Frelimo Frente de Libertação de Moçambique (1962), partido que nasceu como o movimento anti-colonial. A Frelimo se tornou um partido marxista-leninista após a independência, e segue desde 1975 no poder. A Renamo, por sua vez, surgiu como uma guerrilha na antiga Rodésia, apoiada ao longo da guerra civil por África do Sul e Estados Unidos, respectivamente. O antropólogo Luiz Henrique Passador desenvolveu sua tese a respeito dos dilemas contemporâneos vividos pela população de Homoíne em meio às feridas da guerra contribuiu para a publicação do livro de Armando.
} 
colonial, onde as hierarquias protestantes foram mais claramente anticoloniais do que a hieraquia da Igreja Católica. Depois da Independência as grandes igrejas protestantes (presbiteriana, metodista, batista, etc.) acharam que o governo era legítimo na sua missão socialista por resultar de um movimento de libertação, e elas adotaram uma posição "pastoral” em relação aos líderes. Ao contrário, os católicos decidiram desenvolver uma posição "profética” e fizeram críticas públicas contra o governo quando não concordavam como no caso da promoção do ateísmo, dos campos de reeducação e de execuções públicas. Esta distância da Igreja Católica do governo resultou em fortes tensões e explica em grande parte como esta igreja conseguiu mais tarde vir a ser mediadora do Acordo Geral de Paz - tanto o governo moçambicano como a guerrilha da Renamo acharam que esta Igreja era independente politicamente e aceitaram-na como mediadora.

A comunidade sobre qual não falamos aqui são os muçulmanos que, nos tempos coloniais, foram reprimidos pelo governo, a não ser no último período onde alguns foram cooptados estrategicamente. Depois da independência a comunidade muçulmana também sofreu bastante, pois houve um período de forte anticlericalismo por parte da Frelimo, (até 1981/82). Embora representando quase 20\% da população, os muçulmanos tiveram pouca representatividade no governo pós-colonial - os poucos que existiam em lugares de poder eram bastante seculares. Portanto, o Islã tinha pouca visibilidade política antes e depois da independência. A partir de 1982, o governo da Frelimo mudou de posição e tentou controlar as religiões, pedindo para que cada religião tivesse um interlocutor único. Os protestantes tinham que ficar todos no Conselho Cristão, por exemplo, e o governo quis o mesmo para os muçulmanos. Em 1982 criou-se assim um organismo chamado "Conselho Islâmico de Moçambique", com o apoio da Arábia Saudita. Só que por conta da Arábia Saudita e da sua religião fundamentalista escrituralista a maioria dos muçulmanos se negou a juntar-se ao Conselho Islâmico. Daí criaram um "Congresso Islâmico" um ano depois. O governo tentou negar a existência desta organização, mas ficou sem alternativa porque a maioria dos muçulmanos filiou-se ao Congresso. Isto resultou no fim em três organizações no país: o Conselho Islâmico (wahhabita), o Congresso Islâmico (favorável aos sufistas) e a Comunidade muçulmana (cujos donos e adeptos são indo-moçambicanos e paquistaneses) ${ }^{8}$.

Os muçulmanos não tiveram papel nas negociações para acabar a guerra civil. Os primeiros passos para haver negociações foram iniciados pelos protestantes. Para ter mais sucesso incluíram alguns bispos católicos, e isso resultou em negociações no Quênia em 1989, com a mediação de líderes religiosos protestantes e católicos. Quando as negociações enfrentaram dificuldades, sugeriu-se que elas ocorressem em outro país. O governo italiano e a organização católica de Sant'Egidio ofereceram-se e, a partir de 1990, as negociações decorreram em Roma. Desta mediação os protestantes foram excluídos. Há hoje um certo ressentimento por parte dos protestantes por ter iniciado o processo e ter incluído os católicos, para depois serem excluídos por esses do processo de Roma. Os muçulmanos, por sua vez, pediram também para serem incluídos na mediação, mas foram negados. O governo só deu algumas posições aos líderes muçulmanos nas comissões que levaram ao Acordo de Paz de 1992.

8 A ordem sufi ou sufismo em português brasileiro se refere a uma corrente mística do islã. Sobre esta historia, ver Morier-Genoud (2002). Versão em português publicada na Revista Angolana de Sociologia, 15-16, Dezembro de 2015. 
De maneira interessante, houve novas negociações recentemente entre o governo e a Renamo após um pequeno conflito armado entre os dois nos anos 2013-2015, e o primeiro grupo de mediadores chamado foi escolhido tendo em mente as negociações que levaram ao Acordo de Paz de 1992 (Morier-Genoud 2017). O governo e a Renamo escolheram, pois, um grupo de mediadores que eram quase todos religiosos, dentro do qual havia um padre católico, um bispo protestante, e um sheik muçulmano. Portanto, vinte anos depois do primeiro acordo de paz, o modelo da mediação foi reativado e corrigido para incluir todos os religiosos do país ou, melhor, um representante de cada uma das três maiores religiões do país. Houve aí uma continuidade e um eco das negociações do passado, assim como uma tentativa de correção ou melhoria do modelo passado.

Para concluir, notamos no nosso livro sobre a Guerra Civil em Moçambique que ninguém estudou o papel do Islã naquela guerra. Talvez não haja papel do Islã porque o Islã não é um ator, só existem gentes que se identificam como muçulmanos e que podem agir por este motivo, mas também por outros motivos. Eu estudei a Igreja Católica, mas faltam estudos sobre outras igrejas e sobre o Islã. Seria interessantíssimo saber mais sobre como a guerra se desenvolveu no norte do país, se a Renamo usou um discurso sobre o Islã, se o governo usou a carta religiosa no conflito, etc. Estão aí vários estudos fascinantes por fazer. Um campo aberto!

Tomando um pouco do clássico trabalho do Christian Geffray, "A Causa das armas", a gente vê que as mulheres moçambicanas aparecem ou são representadas como muito vulneráveis aos ataques da Renamo ou aos imponderáveis da vida em uma sociedade em guerra. Em sua comunicação a respeito de visualidades em guerra, o senhor comentou a falta de estudos sobre a guerra sob uma perspectiva de gênero. Quais são os trabalhos que abordam esta questão e, a seu ver, quais outras leituras se pode fazer sobre as experiências das mulheres no Moçambique em guerra?

EMG: Há, de fato, poucos trabalhos sobre o gênero e a guerra em Moçambique. Estudos de gênero tem que considerar as mulheres e os homens. Sobre as mulheres existem alguns trabalhos. No nosso livro, há um único artigo. É preciso muito mais, pois é um assunto muito rico e, como disse, pouco estudado. $\mathrm{O}$ que interessa a mim em particular, não é tanto as mulheres como vítimas, mas como protagonistas. E claro que nas guerras a vitimização é muito baseada em gênero, as divisões de papéis sociais são muito duras, há muita violência sexual, etc. Durante a guerra civil em Moçambique, muitas mulheres foram capturadas e entregues a chefes ou combatentes como companheiras ou escravas sexuais. Portanto, há toda esta dinâmica sobre a qual ainda temos bastante por aprender. Mas houve também mulheres que foram comerciantes, que foram chefes na guerrilha ou no exército, governo, ou que ficaram "em casa" a carregar a família enquanto o marido estava na frente de combate. Portanto, é claro que o mundo militar é muito masculino, mas as mulheres existem nele, e numa guerra considerada no seu total, como "fato social total", elas têm um papel importante, diverso e complexo, que deve ser estudado mais e mais largamente. 
Outro aspecto é o da masculinidade. A guerra é muitas vezes vista como um "assunto de homens", mas pouco refletimos, e pouco estudamos, sobre esta mesma masculinidade. Quais são os modelos e os tipos de masculinidades? Qual o modelo de masculinidade hegemônico? Como funciona a homo-sociabilidade nos exércitos, nos campos de batalha, etc? Há aqui, em relação a Moçambique um terreno simplesmente ainda não tocado, não trabalhado. Além disso, precisamos também pensar e estudar as relações de gênero, entre homens e mulheres, dentro da guerra e na vida civil longe dos campos de batalha, dentro dos exércitos, das milícias, etc. $\mathrm{O}$ assunto do gênero é largo e ainda um ponto fraco da historiografia sobre a guerra civil em Moçambique. Espero que alguns pesquisadores vejam aí mais uma oportunidade!

Eric Morier-Genoudé doutor pela State University of New York at Binghamton e Senior Lecturer na Queen's Belfast University, Reino Unido.

Victor Miguel Castillo de Macedo é mestre em Antropologia Social pela UFPR e doutorando em Antropologia Social pelo PPGAS/Museu Nacional/UFRJ.

Francieli Lisboa de Almeida é mestre em Antropologia Social pela UNICAMP e doutoranda no PPGAA/UFPR. É também professora do Instituto Federal do Paraná em Paranaguá.

\section{REFERÊNCIAS BIBLIOGRÁFICAS}

ARMANDO, Hassane. 2018. Tempos de fúria: memórias do massacre de Homoine, 18 de julho de 1987. $1^{a}$ ed. Lisboa: Edições Colibri.

BECKFORD, J ames A. 2003. Social Theory and Religion, Cambridge University Press.

GRANJO, Paulo. 2005. Lobolo em Maputo. Um velho idioma para novas vivências conjugais. Lisboa: Campo das Letras.

HARRIES, Patrick. 2007. Butterfies \& Barbarians. Swiss Missionaries and Systems of Knowledge in South-East Africa. Athens: Ohio University Press.

M’BOKOLO, Elikia. 2011. "Os caminhos da emancipação”. In: África Negra, História e Civilizações, Tomo II. Salvador: EdUFBA.

MORIER-GENOUD, Eric. 2002. “L'Islam au Mozambique après l'indépendance. Histoire d'une montée en puissance”. L'Afrique Politique 2002(1):123-146.

MORIER-GENOUD, Eric. 2011. "Missions and Institutions: Henri-Philippe Junod, Anthropology, Human Rights and Academia between Africa and Switzerland, 1921-1966". Schweizerische 
Zeitschrift für Religions-und Kulturgeschichte (Fribourg) 105:193-219.

MORIER-GENOUD, Eric. 2015. “The Making of a Transnational Historian: Patrick Harries in Lausanne”. Pp.11-13 in Explorations in African History: Reading Patrick Harries, ed. Veit Arlt et al. Basel: BAB.

MORIER-GENOUD, Eric. 2017. "Proto-guerre et négociations. Le Mozambique en crise, 201316". Politique Africaine 145:153-175.

MORIER-GENOUD, Eric, Domingos Rosário e Michel Cahen. 2018. The War Whitin: New Perspectives on the Civil War on Mozambique, 1976-1992. Woodbridge: James Currey.

PETERSON, Derek R. 2012. Ethnic Patriotism and the East African Revival: A History of Dissent. Cambridge University Press.

TAIBO, Ruben. 2012. Lobolo(s) no Moçambique contemporâneo: mudança social, espiritos e experiências de união conjugal na cidade de Maputo. Dissertação de Mestrado, Universidade Federal do Paraná.

ZIMMERMAN, Andrew. 2001. Anthropology and Antihumanism in Imperial Germany. Chicago: University of Chicago Press. 


\section{ANTROPÓlogos, MISSIONÁRIOS E IMAGENS DO CONTINENTE AFRICANO - ENTREVISTA COM ERIC MORIER-GENOUD}

Resumo: Eric Morier-Genoud é Senior Lecturer na Queen's Belfast University, Reino Unido. Fundador e ex-editor-chefe da revista Social Sciences \& Missions ele publicou no ano passado a monografia $\mathrm{Ca}$ tholicism and the Making of Politics in Central Mozambique, 1940-1986. Nesta entrevista, o professor Morier-Genoud, nos conta a respeito da sua trajetória acadêmica e dos itinerários que o levaram a se interessar por atividades missionárias no continente africano. Os objetos e contatos de pesquisa, permitiram a ele transitar entre a História e as Ciências Sociais ao longo de sua carreira. Suas indagações inovadoras oferecem pontos instigantes a respeito das relações entre colonialismo, ciência e religião. Assim, convidamos as leitoras e leitores a seguir as histórias de imagens de missionários africanos ou os dilemas deixados pela guerra civil em Moçambique, como modos de pensar histórias da antropologia. Palavras-chave: Antropologia da África; Antropologia das Missões; História da Antropologia; Moçambique.

\section{ANTHROPOLOGISTS, MISSIONARIES AND IMAGES OF THE AFRICAN CONTI- NENT. INTERVIEW WITH ERIC MORIER-GENOUD}

Abstract: Eric Morier-Genoud is Senior Lecturer on Queen's Belfast University, United Kingdom. Founder and former Editor-in-Chief of the Social Sciences \& Missions Journal, he published last year the monograph Catholicism and the Making of Politics in Central Mozambique, 1940-1986. On this interview, professor Morier-Genoud, tells about his academic trajectory and the itineraries that led his interests for missionary activities on the African continent. The research objects and contacts allowed him to transit between History and Social Sciences throughout his career. His innovating questions offer instigating points concerning the relations amongst colonialism, science and religion. Thus we invite the readers to follow the stories of African missionary images or the dilemmas left by the civil war in Mozambique, as ways of thinking about the histories of anthropology.

Keywords: African Anthropology; Missions Anthropology; History of Anthropology; Mozambique.

RECEBIDO: $13 / 12 / 2019$

APROVADO: $21 / 02 / 2020$ 